\title{
Bibliotecas domiciliares: um estudo de
}

\author{
Adalberto Rego Maciel Filho
}

Professor Titular da Faculdade de Ciências da Administração de Pernambuco - Universidade de Pernambuco. Mestre em Ciência Regional University of Pennsylvania. Doutor em Economia - New School for Social Research New York

Miriam Cunha Aquino

Professora aposentada do Departamento de Ciência da Informação da Universidade Federal de Pernambuco

Islla Silva Soares

Graduanda em Administração pela Faculdade de Ciências da Administração de Pernambuco da Universidade de Pernambuco. Bolsista do Programa de Iniciação Científica da UPE

Camila Alves Silva

Graduanda em Administração pela Faculdade de Ciências da Administração de Pernambuco da Universidade de Pernambuco. Bolsista do Programa de Iniciação Científica. Bolsista do Fundo de Pesquisa da FCAP-UPE

Pesquisa empírica sobre o papel da biblioteca domiciliar e do hábito de leitura dos pais dos professores da Universidade de Pernambuco, na escolaridade dos educadores. 107 professores foram entrevistados (24 especialistas, 60 mestres, 25 doutores). Constatou-se que a residência na infância dos professores da UPE, na média, teria uma biblioteca domiciliar de 119,7 volumes (no Fundamental I); e seus pais, na maioria, liam e tinham quase 11,1 anos de estudo. Simulações também foram realizadas, analisando as relações entre o tamanho das bibliotecas domiciliares e desempenho escolar com dados do PISA, referentes a 27 países e, no caso do Brasil, com 2000 alunos. Os resultados acompanham as conclusões apresentadas na revisão da literatura, que apontam uma correlação positiva entre as duas variáveis. São sugeridas políticas que poderiam influenciar programas já existentes e novos projetos, ou, ainda, 
incentivar novas pesquisas na área de bibliotecas domiciliares e públicas.

Palavras-chave: Biblioteca domiciliar; Hábito de leitura; Escolaridade dos filhos.

\section{Libraries home: a case study}

Empirical research on the role of the home library and reading habits of the teachers ' parents at the University of Pernambuco in the educators 'schooling. 107 teachers were interviewed (25 doctors, 60 master and 24 with after graduation courses). The results were: the teachers' residence in their childhood, on average, had a library with 119.7 volumes; the majority of their parents had reading habits and had nearly 11.1 years of study. Simulations were also performed analyzing the relationship between the size of the home library and school performance with PISA data relating to 27 countries and, in the case of Brazil, with 2000 students. The results follow the conclusions presented in the literature review which indicate that there is positive correlation between the two variables. Policies are suggested that could influence existing programs, new projects or encourage further research in the area of household and public libraries.

Keywords: Home library; Reading habit; Schooling.

Recebido em 20.09.2012 Aceito em 08.02.2013

\section{Introdução}

De acordo com World Bank (2007, p. 19):

As evidências acumuladas das análises dos resultados econômicos são que a qualidade da educação- medida em resultados baseados em habilidades cognitivas - produz efeitos poderosos. Os ganhos individuais são sistematicamente relacionados com habilidades cognitivas. A distribuição de habilidades na sociedade aparece proximamente relacionada com a distribuição de renda. $E$, talvez mais importante, 0 crescimento econômico é fortemente afetado pelas habilidades dos trabalhadores. 
Ainda, "[...] qualidade da educação é causalmente relacionada com resultados econômicos. Para ser preciso, qualidade pode vir da educação formal, dos pais, ou de outras influências nos estudantes" (WORLD BANK, 2007, p. 20).

No Brasil, segundo as estimativas do World Bank (2007, p. 13), aproximadamente $66 \%$ dos alunos eram analfabetos funcionais em 2000. Em 2009, segundo o Sumário Executivo do Programa Internacional de Avaliação de Alunos (PISA) (ORGANISATION FOR ECONOMIC COOPERATION AND DEVELOPMENT -OECD, 2010), a redução ocorrida em 2009, em relação a 2000, foi de 6,2\%, ou seja, passaram a corresponder a $61,91 \%$.

Estudos recentes indicam que uma das variáveis importantes que contribuem para explicar o aumento da escolaridade (EVANS et al., 2010) e desempenho escolar (PARK, 2008) é a quantidade de livros existentes nas residências dos alunos, ou seja, a biblioteca domiciliar.

Motivada por essas questões, a presente pesquisa procura investigar as características da biblioteca domiciliar e suas relações com a escolaridade de professores da Universidade de Pernambuco (UPE). Analisa, ainda, o hábito de leitura dos pais deles e outras particularidades. Compõe-se de seis partes: introdução, revisão de literatura, análise dos resultados da pesquisa, análise dos dados do Pisa, discussão dos resultados e considerações finais, que incluem algumas proposições de políticas públicas.

\section{Revisão de literatura}

Nesta seção, discutem-se pesquisas empíricas realizadas com a preocupação de investigar os efeitos das bibliotecas domiciliares e do hábito de leitura na educação dos indivíduos, além de outras variáveis.

Graaf, Graaf e Kraaykamp (2000) preocuparam-se com a análise e teste estatístico de algumas hipóteses concorrentes, que buscam explicar o sucesso educacional dos alunos na Holanda.

Trabalharam-se os dados do Netherlands Family Survey. (ULTEE E GANZEBOOM, 1993 apud Graaf, Graaf e Kraaykamp, 2000, p.100). Do total de 1.800 entrevistados, analisaram 1.479. As variáveis utilizadas foram: anos de educação, anos de educação dos pais, status ocupacional dos pais, situação financeira dos pais, capital cultural dos pais, participação dos pais nas belas-artes, hábito de leitura dos pais, gênero, Cohort (grupo de indivíduos que nasceram em um dado período) e família separada.

As evidências empíricas encontradas por Graaf, Graaaf e Kraaykamp (2000, p. 107), empregando modelos de regressão, podem, assim, ser resumidas:

a- As leituras dos pais são um efetivo indicador do sucesso escolar, especialmente para as crianças cujos pais tenham um nível baixo de escolaridade (p. 92); 
b- [...] hábitos familiares de leitura são mais importantes para as crianças de baixos e médios socioeconômicos backgrounds e menos importante para os de alto background socioeconômico (p. 108); e

c- Hábitos familiares de leitura proporcionam vantagens nas carreiras educacionais das crianças.

Os resultados chamam a atenção para a importância da leitura dos pais na educação dos filhos, sobretudo para as famílias de baixa escolaridade e renda.

Park (2008) analisou diversos fatores que, em 25 países, contribuíam para o desempenho na leitura das crianças da quarta série do primeiro grau. O Brasil não foi incluído.

As variáveis investigadas, relativas ao ambiente literário doméstico, foram: índices de atividades alfabetizantes precoces nas famílias (os pais liam livros paras as crianças, contavam histórias, cantavam músicas, brincavam com alfabeto de brinquedo e jogos de palavras, liam placas ou nomes); hábito de leitura; tamanho da biblioteca domiciliar em livros; e escolaridade do pai. Com relação à quantidade de livros, utilizou-se uma escala de cinco unidades: 0-11 livros (1), 11-25 (2), 26-100 (3), 101-200 (4), e mais de 200 (5).

O modelo usado foi: a habilidade de leitura medida pelas notas do teste depende do ambiente literário residencial supracitado, background socioeconômico (educação dos pais), localização da escola em que o aluno estudou (urbana, suburbana e rural), sexo, número de crianças, estrutura familiar (famílias com um adulto ou com dois) e, por último, se a língua tinha status minoritário (se ele fala a língua em que o teste é escrito ou não) (PARK, 2008, p. 493-494).

Os resultados encontrados foram: as maiores médias de livros nas bibliotecas familiares estavam na Suécia $(3,7)$, Noruega $(3,6)$ e Islândia $(3,5)$. As médias mais baixas foram as da Argentina $(2,0)$, Colômbia $(2,9)$ e Irã $(1,8)$. Observe-se que os números acima têm que ser lidos com o auxílio da escala de 1 a 5 .

Uma visão dos tamanhos médios das bibliotecas pode ser obtida a partir de uma aproximação com os dados de Park (2008, p. 496): Suécia 132,3 livros; Noruega 122,4; Islândia 112,5; Argentina 19,22; Columbia 18,1 ; e Iran $16,7^{1}$.

Park (2008, p. 496) assim resume as evidências:

Os índices de atividades domésticas alfabetizantes na infância $(r=0,52)$, os índices de atitudes paternas com relação à leitura (hábito de leitura) $(r=0,46)$, e o número de livros em casa $(0,83)$ também mostram uma considerável relação

\footnotetext{
${ }^{1}$ Para obtê-los, utilizou-se o valor médio do intervalo classe e acrescentou-se o valor igual ao percentual do segundo intervalo de classe. Ex.: Suécia 3,7 - 3 igual ao valor médio $(100+26) / 2=63 ; 0,7=70 \%$ do próximo intervalo( 200-101=99) $0,7 \times 99=69,3$. Valor da Suécia $=63+69,3=132,3$.
} 
positiva com a média nacional das notas em leitura, indicando que países com um ambiente mais favorável para leitura tendem a apresentar uma melhor média no desempenho em leitura.

Verificou-se, no experimento, a existência de uma defasagem (gap) bastante elevada entre os alunos cujos pais tinham educação universitária e aqueles cujos pais tinham menos do que o ensino médio (colegial). Introduzindo-se no modelo as variáveis índice de atividades alfabetizantes, hábito de leitura e número de livros em casa, observou-se uma redução considerável na referida defasagem. Na Hungria, a diminuição chegou a $25 \%$.

O índice de atividades alfabetizantes, hábito de leitura dos pais e número de livros em casa são significativamente associados com o desempenho na leitura das crianças em 25 países, mesmo controlando o experimento pela educação dos pais e outras características. "No entanto, - efeito da educação dos pais no desempenho da leitura das crianças permanece substancial mesmo depois de se considerar o ambiente literário doméstico" (PARK, 2008, p. 502).

O estudo realizado por Wobmann (2003, p. 143), utilizando um modelo de função de produção educacional, "evidencia que a educação dos pais e o número de livros no domicílio estão fortemente relacionados com o desempenho educacional do estudante".

Destaca-se, assim, a importância da biblioteca domiciliar na educação:

O nível educacional alcançado pelos pais dos estudantes é positivamente relacionado com o desempenho educacional dos estudantes. O efeito da variável livros em casa como uma variável aproximada (proxies) para o ambiente educacional e social na casa dos estudantes foi ainda mais forte (WOBMANN, 2003, p. 133).

Evans et al. (2005,) pesquisaram as relações entre o tipo de atividade ocupacional, ordenadas de acordo com o critério para status de Kelley, e as variáveis: anos de educação, livros na casa dos pais; educação dos pais; status da ocupação dos pais; ocupação paterna autônomo, pai proprietário, pai supervisor - e gênero. Explicam que a quantidade livros é uma boa representante das variáveis culturais. Ela estava correlacionada com as demais.

O experimento utilizou dados de 31 sociedades e informações de 58.944 indivíduos (EVANS et al. , 2005). O trabalho evidenciou o impacto exercido pela biblioteca domiciliar no nível de ocupação dos habitantes dos diversos países investigados. A influência observada se dá indiretamente. No primeiro momento, influencia o nível de escolaridade, e este, o nível ocupacional posteriormente. 
O estudo de Evans et al.(2010) se inicia com a discussão sobre a teoria a ser utilizada na pesquisa e contrasta dois modelos: o modelo de cultura acadêmica e o modelo de enclausuramento das elites. Optam pelo primeiro, tendo como propósito averiguar se "[...] a cultura acadêmica melhora a aprendizagem e o desempenho na escola." (EVANS et al., 2010, p.172).

O termo cultura é utilizado como atividade diária - "conjunto de práticas rotineiras e preferências que são ocupadas com objetos materiais (livros, neste caso) e com atividades (leitura, conversa sobre livros, uso do conhecimento)". (EVANS et al., 2010, p. 173).

Discutem a existência de rendimentos marginais decrescentes com relação aos bens culturais. Ou seja, à medida que a quantidade de livros lidos vai aumentando, o impacto na educação vai diminuindo. "Depois de se conseguir compreender Hamlet, 0 vocabulário e a estratégia interpretativa adicional requeridas para se ler MacBeth é apenas um pequeno avanço". (EVANS et al.,2010, p.173-174).

No modelo de cultura acadêmica, se pressupõe que a interação entre as variáveis número de livros e educação dos pais seja a seguinte: nas famílias em a que escolaridade dos pais seja elevada, acredita-se que o efeito dos números de livros nas bibliotecas domésticas seja menor sobre a escolaridade do filho, enquanto naquelas famílias com menor nível de escolaridade, o efeito das bibliotecas domésticas seja maior. (EVANS et al., 2010, p.174)

O número de livros, de acordo com Evans et al. (2010, p. 5), pode ser utilizado como índice de cultura acadêmica. Encontra-se correlacionado com outros aspectos da cultura acadêmica, incluindo quantos livros os pais leem de novelas sérias ou de poesia, de ciências, matemática, tecnologia e outros livros sérios, como história e biografia, ida à biblioteca, etc. (GRAAF,1986 apud EVANS et al., 2010, p. 175).

Evans et al. ( 2010, p.174) elaboraram três hipóteses:

1- Cultura acadêmica confere vantagens educacionais: a participação dos pais na cultura acadêmica incrementará os resultados escolares das crianças, independentemente da educação formal dos pais e classe social [...];

2-os maiores ganhos estão no nível mais baixo: o aumento da cultura acadêmica tem o maior impacto nas crianças de famílias com níveis mais baixos de escolaridade acadêmica. (Ex.: o aumento na biblioteca domiciliar de 10 para 20 livros é mais importante do que o de 40 para 50 livros); e

3-interação com a educação formal: a cultura acadêmica tem um maior impacto na educação das crianças cujos pais possuem um menor nível de escolaridade.

(Ex: o aumento de 10 para 20 livros nas famílias em que os pais terminaram somente o primário ajudará mais do que o de 
10 para 20 livros nas famílias em que ambos os pais concluíram o ensino médio).

Para testar as hipóteses supracitadas, foi utilizado um modelo estatístico no qual a educação era explicada pelas seguintes variáveis: logaritmo do número de livros na casa dos pais, educação dos pais, ocupação dos pais, pai proprietário, pai pequeno burguês, pai supervisor, gênero, logaritmo do número de livros na casa dos pais vezes a educação dos pais, Europa ocidental, PIB do país quando o entrevistado tinha 15 anos de idade ${ }^{2}$. (EVANS et al., 2010, p. 177).

Os resultados encontrados quanto ao número de livros em residências são os seguintes: $10 \%$ cresceram sem livros; $23 \%$ com 10 livros; 16\% com 25 livros; 33\% com 75 livros; e 18\% com centenas de livros. (EVANS et al.,2010, p.179).

Mostraram, com o auxílio de um gráfico, que existe uma relação entre as variáveis número de livros na residência e os anos de educação. De 0 a 50 livros, a relação da quantidade de livros com a escolaridade é quase uma reta com inclinação positiva e com elevado coeficiente de correlação. De 50 a 100 livros, começa a existir uma redução na declividade. A partir de 100 até 500 livros, os dados número de livros e anos de estudo tornam-se quase paralelos em relação ao eixo horizontal, ou seja, apresentam rendimentos decrescentes.

As crianças sem livros em casa, na média, chegaram há sete anos de estudo. As com poucas dúzias de livros, completaram 11 anos de estudo. Crianças cujos pais possuíam muitos livros chegaram a 14 anos de educação, ou seja, a junior college (faculdade de dois anos). (EVANS et al., 2010, p.179).

Dessa forma, sete anos de escolaridade separam os que cresceram sem livro dos que cresceram com mais de 500 livros. Cada livro adicional está associado a um maior ganho em resultados educacionais nas famílias com poucos livros do que nas famílias que já têm muitos livros. (EVANS et al.,2010, p.179).

Outras constatações de Evans et al. (2010, p.179):

O tamanho da biblioteca doméstica tem um efeito muito substancial nas realizações educacionais, mesmo depois de controlar o efeito da educação dos pais, status da ocupação dos pais e outras características do background familiar.

Crescer numa casa com mais de 500 livros impulsiona uma criança a alcançar mais 3,2 de anos estudos, na média, do que se ela tivesse crescido numa casa com poucos livros ou nenhum.

[...] a diferença entre os de uma casa sem livros e uma com uma biblioteca com 500 livros é tão grande quanto a diferença entre ter pais somente alfabetizados (três anos de educação) e

\footnotetext{
${ }^{2}$ As especificações encontram-se em Evans et al. (2010).
} 
ter os pais com educação universitária. Uma casa com livros é tão importante quanto ter pais com educação universitária (15 ou 16 anos de educação).

O estudo evidencia a importância da biblioteca domiciliar (quantidade de livros) na escolaridade dos filhos. Ressalta, sobretudo, que o efeito é mais acentuado nas residências em que os pais têm menor escolaridade e renda mais baixa e quando a biblioteca residencial é menor.

\section{Análise do estudo empírico}

Os estudos da revisão de literatura enfatizam o papel da biblioteca domiciliar e do hábito de leitura dos pais na educação dos filhos. Analisam-se, nesta seção, essas variáveis no contexto da Universidade de Pernambuco. A discussão compõe-se de duas partes: a natureza da amostra e dos dados colhidos e a análise dos resultados.

\subsection{Dados e características da amostra}

Escolheu-se para realizar a investigação um subgrupo dos professores da Universidade de Pernambuco, cobrindo-se os anos em que eram estudantes. A amostra é composta por 109 docentes, dos quais, 61 são da Faculdade de Ciências da Administração de Pernambuco (FCAP) (todo o corpo docente) e 48 da Faculdade de Formação de Professores de Nazaré da Mata. A Universidade de Pernambuco (UPE) tem um total de 920 professores distribuídos em diversos cursos (administração, medicina, engenharia etc.) ministrados nas várias unidades de ensino que a compõem.

Utilizou-se um questionário composto de 12 perguntas, divididas em duas partes: na primeira, os dados de identificação dos professores (idade, escolaridade ) - e, na segunda, os dados que possam ter influenciado na juventude dos professores sua formação acadêmica (número de livros que havia na casa dos pais, escolaridade e hábitos de leitura dos pais, hábitos culturais, ocupação profissional dos pais e renda familiar).

Os anos de estudo dos professores foram estimados de acordo com os graus de escolaridade e titulações deles, adotando-se: 4 ou 5 anos para graduação (dependendo do curso); 1 ano para especialização; 3 anos para mestrado; e 5 anos para doutorado, tomando-se a duração média usual de tais titulações.

$\mathrm{Na}$ tentativa de identificar a classe social dos entrevistados na juventude, tomou-se por base o Critério Brasil (PIEDADE, 2009). Trata-se de um sistema baseado na soma de pontuações estabelecidas de acordo com a posse de bens de um domicílio, aliado ao grau de escolaridade do chefe de família. Como os itens de conforto utilizados para a classificação da situação socioeconômica das famílias mudam ao longo do tempo, já que novas tecnologias são criadas e que produtos com alto grau de 
predição do estrato econômico tornam-se massificados, as idades dos professores foram levadas em conta, para que a tabela aplicada contemplasse os bens de consumo relevantes no Brasil durante a juventude deles. Para aqueles cuja juventude deu-se na década de 70 ou anterior a isso, foi utilizado o critério estabelecido pela Associação Brasileira de Anunciantes (ABA), o Critério ABA (1970). Já os docentes que foram jovens nos anos 80 , a tabela empregada para a identificação da situação socioeconômica foi baseada no Critério ABA-ABIPEME (1982), desenvolvida pela Associação Brasileira dos Institutos de Pesquisa de Mercado (ABIPEME), com a aprovação da ABA. E, para os professores mais jovens, o Critério Brasil (1997) foi o modelo usado ${ }^{3}$.

\subsection{Resultados}

A amostra é composta por 24 especialistas, 60 mestres e 25 doutores. Possuem média de 22,6 anos de anos de estudos formais, com desvio padrão de 3,3 anos. A média de anos de estudo dos pais dos docentes é de 11,11 anos, enquanto que a das mães é de 11,01 . Possuem os pais dos docentes, em média, quase o segundo grau completo.

Tabela 1- Escolaridade dos pais dos professores, $8 \%$

\begin{tabular}{lcc}
\hline Escolaridade & Pai (\%) & Mãe (\%) \\
\hline Sem primário & 0,9 & 0,9 \\
Primário incompleto & 13,9 & 10,1 \\
Primário & 10,2 & 8,3 \\
Ginásio incompleto & 3,7 & 3,7 \\
Ginásio & 9,3 & 12,8 \\
Segundo grau incompleto & 14,8 & 17,4 \\
Segundo grau & 11,1 & 14,7 \\
Terceiro grau incompleto & 9,3 & 10,1 \\
Terceiro grau completo & 12,0 & 14,7 \\
Pós-graduado & 14,8 & 7,3 \\
\hline Total & $\mathbf{1 0 0}$ & $\mathbf{1 0 0}$
\end{tabular}

Fonte: Dados da pesquisa.

Constatou-se que, individualmente, $28,7 \%$ dos pais e $22,9 \%$ das mães não concluíram o ginásio. A análise por domicílio, ou seja, da escolaridade de cada residência, no entanto, mostra que $80,73 \%$ deles tinham pelo menos um dos pais com o ginásio completo.

Em relação à leitura, a maioria dos pais e mães dos docentes possuía hábito de leitura.

3 Vide Piedade (2009), para mais detalhes sobre os critérios supracitados. 
Tabela 2- Hábito de leitura dos pais dos professores

\begin{tabular}{lcc}
\hline Frequência de leitura dos pais & Pai (\%) & Mãe (\%) \\
\hline Regular ou constante & 61,1 & 52,3 \\
Ocasional & 24,1 & 29,4 \\
Não tinham hábito de leitura & 14,8 & 18,3 \\
\hline Total & $\mathbf{1 0 0}$ & $\mathbf{1 0 0}$ \\
\hline
\end{tabular}

Fonte: Dados da pesquisa.

Os dados da Tabela 2 ilustram a situação de cada pai ou mãe individualmente. A análise realizada por domicílio, mostra que somente em 3,7\% deles os pais não tinham hábito de leitura. Significa que na casa onde o pai $(15 \%)$ ou a mãe (18\%) não lia individualmente, isso era compensado por parceiro que lia. Resumindo: 96,3\% dos professores, durante a infância, cresceram em lares onde pelo menos um dos pais tinha hábito de leitura.

A média da biblioteca residencial dos professores era de 160 livros quando cursavam o ensino fundamental I (antigo primário). No ensino fundamental II (antigo ginásio), essa média subiu para 170 livros, alcançando 210 livros na época do ensino médio (antigo científico/clássico). Os valores médios, quando retiradas as cinco bibliotecas com 1000 livros, caem, respectivamente, para 119,27, 130,48, 171,92 .

Na Tabela 3, observa-se o crescimento da biblioteca domiciliar ao longo dos níveis de escolaridade e que as unidades de 50 livros aumentaram de $15 \%$ para $20 \%$ do total e as de 200 passaram de $13 \%$ para $21 \%$. As de 100 livros reduziram-se de $16 \%$ para $11 \%$.

Nota-se, na Tabela 3, que: 55\% das bibliotecas QL1 tinham, aproximadamente, até 50 livros; $15 \%$ em torno de 100; e $29 \%$, aproximadamente, acima de 200 livros.

Tabela 3- Tamanho e quantidade das bibliotecas domiciliares, segundo a fase da vida e nível de ensino dos professores da UPE

\begin{tabular}{ccccccc}
\hline Livros & $\begin{array}{l}\text { Bibliotecas QL1 } \\
\text { Infância/Fund.I }\end{array}$ & \multicolumn{3}{c}{$\begin{array}{l}\text { Bibliotecas QL2 Pré- } \\
\text { adolescência /Fund.II }\end{array}$} & \multicolumn{2}{c}{$\begin{array}{l}\text { Bibliotecas QL3 } \\
\text { Adolescência/Médio }\end{array}$} \\
\hline $\begin{array}{c}\text { (entorno } \\
\text { de) }\end{array}$ & Quantidade & $\%$ & $\begin{array}{c}\text { Quantida } \\
\text { de }\end{array}$ & $\%$ & Quantidade & $\%$ \\
\hline 0 & 2 & 1,8 & 1 & 0,9 & 1 & 0,9 \\
2 & 2 & 1,8 & & & & 5,5 \\
10 & 20 & 18,4 & 16 & 14,7 & 6 & 19,3 \\
20 & 20 & 18,4 & 18 & 16,5 & 21 & 20,2 \\
50 & 16 & 14,7 & 19 & 17,4 & 22 & 11,0 \\
100 & 17 & 15,6 & 18 & 16,5 & 12 & 21,1 \\
200 & 14 & 12,8 & 19 & 17,5 & 23 & 15,6 \\
500 & 13 & 11,9 & 13 & 11,9 & 17 & 6,4 \\
1000 & 5 & 4,6 & 5 & 4,6 & 7 & 100 \\
\hline Total & 109 & 100 & 109 & 100 & 109 &
\end{tabular}


É interessante observar o tamanho médio da biblioteca domiciliar na juventude dos professores, segundo sua formação acadêmica. Na casa dos pais dos atuais professores da área de artes e design, havia 50 livros; na dos de exatas, 136,3; na dos de saúde, 145,7; na dos de humanas, 186,3; na dos de administração e negócios 297,7; e na dos de meio ambiente, 350 livros

Quanto ao perfil da renda familiar observado na juventude dos docentes: 36 professores pertenciam a família da classe A $(33 \%), 47$ da classe B $(43 \%), 21$ da classe C (19\%) e cinco da classe D $(5 \%)$.

É possível perceber que há uma relação positiva entre a quantidade média de livros na biblioteca familiar (QL1), na época da juventude dos professores com 0 hábito de leitura de seus pais. Nas análises subsequentes, seguindo o trabalho de Park (2008), utilizam-se os dados das bibliotecas residenciais no primário (QL1). A quantidade média de livros aumenta à medida que o hábito de leitura dos pais torna-se mais assíduo. É esperado que um leitor frequente possua mais livros em relação aos sem o hábito regular de leitura. Essa relação pode ser observada pelas equações ${ }^{4}$.

Analisando-se a relação entre a quantidade de livros e escolaridade, constata-se: a relação entre os anos de estudos dos professores e a quantidade de livros possuídos durante a juventude é bastante acentuada, até o ponto em que a biblioteca alcança o número de 50 livros, reduzindose a intensidade da correlação com o crescimento da biblioteca domiciliar. As regressões realizadas para as respectivas quantidades de livros ilustram esse aspecto ${ }^{5}$.

A diminuição do valor do $R^{2}$ indica que a relação linear existente entre as variáveis estudadas diminui, à proporção que o acervo vai aumentando. Os dados aproximam-se de uma curva logística, terminando quase paralela ao eixo horizontal, coincidindo com o observado por Evans et al. (2010). Constata-se rendimento decrescente entre a quantidade de livros e a variável anos de estudos formais.

Separando a amostra por classes de renda, percebe-se, no entanto, que, à medida que a renda sobe, a relação fica menos precisa.

Para as classes C e D: NAE $=19,70+0,16$ QL1 $R^{2}=0,962$

$$
(31,8) \quad(7,2)
$$

Para as classes A e B: NAE $=21,04+0,06$ QL1 $R^{2}=0,693$

$$
(35,0) \quad(2,6)
$$

A análise foi realizada para os casos em que a biblioteca familiar era de até 50 livros. As regressões foram feitas para cada classe de renda. Os

\footnotetext{
$4 \mathrm{QL1}=79,46 \mathrm{HLP}-73,4 \quad \mathrm{R}^{2}=0,8759 ;$

$\mathrm{QL1}=95,69 \mathrm{HLM}-64,0 \quad \mathrm{R}^{2}=0,8823$

Nelas, QL1 é a quantidade de livros, HLP e HLM são os hábitos de leitura do pai e mãe, respectivamente, e $R^{2}$ é o coeficiente de determinação.

${ }^{5} \mathrm{NAE}=21,114+0,0592 \mathrm{QL1}, \mathrm{R}^{2}=0,9417$ para o acervo de até 50 livros; $(101,2) \quad(6,9)$

$\mathrm{NAE}=21,649+0,0162 \mathrm{QL} 1, \mathrm{R}^{2}=0,3116$ para o acervo de até 100 livros; $(38,7) \quad(1,3)$

$\mathrm{NAE}=22,172+0,0009 \mathrm{QL} 1, \mathrm{R}^{2}=0,0907$ para o acervo total (até1000 livros) $(97,1) \quad(0,8)$

Nelas, NAE significa o número de anos de estudo. O teste t encontra-se entre parênteses, nas equações acima.
} 
resultados mostram um ordenamento em que os $R^{2}$ das equações diminuíam com aumento das rendas. Salvo para a classe A, para a qual a relação tornou-se negativa. O teste $t$ encontra-se entre parênteses, nas equações acima.

A quantidade média de livros também guarda uma relação positiva com as classes sociais dos pais durante a infância dos professores. A média de livros é maior na residência daqueles docentes que tinham maior renda. A equação abaixo mostra a correlação entre tais variáveis ${ }^{6}$.

Poder-se-iam resumir os resultados assim: a residência na infância dos professores da UPE, na média, teria uma biblioteca domiciliar de 119,7 volumes (no Fundamental I). O valor é comparável ao da Noruega. (PARK, 2008). Seus pais, na maioria, liam e tinham quase 11,1 anos de estudo.

\section{Considerações adicionais: os dados do Pisa}

Os dados analisados, nesta seção, são oriundos dos questionários preenchidos pelos participantes, com a idade de 15 anos, do teste Pisa 2009 (OECD,2010), provenientes de 72 países. O tamanho da amostra é calculado, buscando gerar médias confiáveis por país. Por exemplo, no Brasil, foram 950 escolas e 20.127 alunos, nos Estados Unidos foram 165 escolas e 5.233 alunos.

Os dados do Pisa 2009 (TODOS PELA EDUCAÇÃO, 2012) utilizados foram: quantidade de livros nas residências; e desempenho dos alunos nos testes de leitura, ciências, matemática e suas respectivas bibliotecas domiciliares.

\subsection{Quantidade de livros}

Nos países da OECD, 73,25\% das residências têm mais de 25 livros. Na América Latina, representada na amostra por sete países (Brasil, Uruguai, Argentina, Chile, México, Peru e Colômbia), cai para 40,88\% das residências. No Brasil, somente 30\% têm mais de 25 livros.

$\mathrm{Na}$ amostra de 72 países, o maior percentual de lares com menos livros é o Brasil, com 39,52\%, tendo menos de 10 livros. No estudo com professores da FCAP, esse valor é de 21,90, próximo ao do Chile, com $20,37 \%$ e ao dos Estados Unidos, com 19,55\%.

\subsection{Relação entre quantidade de livros e notas escolares}

Os dados coletados pelo Pisa 2009 permitem realizar alguns experimentos.

\footnotetext{
${ }^{6} \mathrm{QL} 1=-93,95+86,46 \mathrm{R} \quad \mathrm{R}^{2}=0,8978$.

$(-0,9) \quad(4,2)$

$\mathrm{R}$ representa a renda, $\mathrm{R}^{2}$ o coeficiente de determinação e o teste t encontra-se entre parênteses, na equação acima.
} 
Correlacionando as notas médias de leitura, matemática e ciências de 72 países com a quantidade de livros (nos intervalos de 0-10, 11-25 e 26-100 livros ) que os estudantes brasileiros possuíam nas suas residências, obtêm-se os seguintes resultados:

$\mathrm{MNL}=0,8151 \mathrm{QL}+414,17 \mathrm{R}^{2}=0,9047$

$M N M=10,7574 Q L+410,73 R^{2}=0,9238$

$\mathrm{MNC}=0,7866 \mathrm{QL}+422,1 \mathrm{R}^{2}=0,9056$

Neles, MNL é a média de notas em leitura; MNM, a das notas em matemática; MNC, a de notas em ciências; e QL é a quantidade de livros na residência.

No caso brasileiro, os valores para os coeficientes e correlação $\left(R^{2}\right)$ para leitura, matemática e ciência são, respectivamente: 0,9635, 0,9607 e 0,9574 .

Observa-se, portanto, uma correlação positiva acentuada entre a quantidade de livros e as notas alcançadas nos testes das três disciplinas nos dois experimentos, tal como constataram Evans et al. (2010) e o estudo empírico com os professores da FCAP.

Os rendimentos decrescentes também aparecem nesses casos. Ao se calcular a correlação com os valores para as bibliotecas domiciliares, acrescentando os intervalos de 101-200, 201-500 e acima de 500 livros, a relação linear tende a desaparecer e observa-se nos dados tendência ao paralelismo com relação ao eixo horizontal.

Os dados mostram o tamanho relativamente menor das bibliotecas residenciais brasileiras em relação as dos 72 países. Confirmam a correlação observada entre quantidade de livros e desempenho escolar como em Park (2008) e os rendimentos decrescentes discutidos na Seção 3.

"Em todos os países, estudantes que apreciam muito a leitura têm um desempenho significativamente melhor do que os estudantes que gostam de ler o mínimo". (OECD, 2010).

\section{Discussão dos resultados}

Evans et al.( 2010) apresentam evidências de correlações positivas entre a quantidade de livros na biblioteca residencial e escolaridade. Mostram, ainda, que a influência é mais acentuada nas famílias de baixa escolaridade e renda. Chamam atenção, ainda, para o maior impacto das bibliotecas menores na escolaridade, tendo em vista que constataram rendimentos marginais decrescentes em relação aos bens culturais.

Os resultados de Park (2008) mostram uma considerável correlação positiva entre os índices de atividades domésticas alfabetizantes na infância, índices de atitudes paternas com relação à leitura (hábito de leitura) e o número de livros em casa, também com a média nacional das notas em leitura de alunos da quarta série do primeiro grau. 
Os resultados do estudo da UPE corroboram algumas das evidências identificadas por Evans et al.(2010): rendimentos marginais decrescentes com relação ao número de livros depois de alcançar o total 50 livros na biblioteca residencial; correlação elevada entre escolaridade (número de anos de estudo) e número de livros na infância (QL1) existentes na casa dos pais do professor até 50 livros; correlação positiva entre escolaridade nas classes de renda mais baixas ( $C$ e $D$ )e quantidade de livros (QL1). À medida que a renda sobe, a correlação diminui. Cabe salientar, que este trabalho analisou as correlações entre algumas variáveis individualmente, em contraste com o modelo multivariável de Evans et al. (2010), que possibilita a mensuração de impactos das variáveis na educação, de forma conjunta.

No experimento com os dados do PISA, constatou-se a correlação positiva entre a média das notas de matemática, línguas e ciência e o número de livros nas residências dos 72 países pesquisados, inclusive no Brasil, para bibliotecas com até 100 livros, no universo de estudantes de 15 anos de idade. Esses resultados corroboram Park (2008, p. 496): "Número de livros em casa também mostram uma considerável relação positiva $(0,83)$ com a média nacional das notas em leitura".

Quanto ao número de livros das bibliotecas residenciais:

a) Evans et al.(2010, p. 9), entrevistando 73.249 jovens, encontraram que $10 \%$ cresceram sem livros; $23 \%$ com 10 livros; $16 \%$ com 25 livros; 33\% com 75 livros; 18\% com centenas de livros; e

b) no universo do PISA (2009), composto por alunos com até 15 anos de 72 países, 39,52 \% dos alunos brasileiros têm menos de 10 livros nas residências, a menor percentagem entre os países investigados;

As constatações supracitadas sobre a importâncias das bibliotecas domiciliares na escolaridade e desempenho acadêmico, assim como a presença relativamente baixa de livros nos lares brasileiros, sinalizam a necessidade de se implementar políticas, buscando incentivar a criação e expansão das bibliotecas domésticas e públicas.

\section{Considerações finais}

A literatura pesquisada apresenta diversos estudos que utilizam diferentes variáveis para testar suas hipóteses. Ressalta-se a existência da associação entre biblioteca domiciliar e escolaridade (EVANS et al., 2010), desempenho escolar (PARK, 2008; WOBMANN, 2003) e desempenho ocupacional (EVANS et al., 2005). Graff, Graff, e Kraaghamp (2000) apontam, ainda, a importância do hábito de leitura dos pais no sucesso educacional dos filhos. Evans et al. (2005) utilizaram, também, a variável hábito de leitura. 
Evans et al. (2010, p.171) resumem, assim, os seus resultados: "[...] crianças crescendo em casas com muitos livros conseguem obter três anos a mais de escolaridade do que as crianças de casas sem livros, independentemente da educação, ocupação e classe social dos pais".

Observou-se na pesquisa da UPE que um percentual elevado dos professores possuía uma biblioteca domiciliar (somente dois não tinham biblioteca e dois dispunham apenas de 2 livros); seus pais, em sua maioria, tinham hábito de leitura (somente em quatro residências os pais não liam); a quantidade de livros apresenta uma relação direta com a classe social do entrevistado; e os anos de estudos dos professores estão associados à quantidade de livros em suas bibliotecas familiares na juventude, sobretudo para os domicílios com até 50 livros.

As evidências, com a análise dos dados do Pisa para 72 países, corroboram os resultados de Park (2008) em relação ao desempenho escolar, no entanto se referem a diferentes níveis de escolaridade.

Os resultados obtidos da UPE são representativos de amostra que tem escolaridade elevada e diversificada ( 20 cursos superiores distintos). Os do Pisa são representativos do ensino médio brasileiro para alunos com 15 anos. As características identificadas poderiam ajudar no planejamento de políticas públicas, sobretudo no Nordeste ${ }^{7}$.

Nesse sentido, as evidências empíricas poderiam influenciar programas já existentes, projetos em discussão ou sugerir outros, como, por exemplo:

a) priorizar, no programa Vale-Cultura ${ }^{8}$, os livros, sobretudo literatura compatível com o ensino fundamental I, para formação de biblioteca domiciliar. Direcionar o programa para os mais pobres (por exemplo, famílias com renda de até dois salários mínimos), estrato em que foi observado, na revisão da literatura, o maior retorno em termos de escolaridade;

b) direcionar o Cartão-Livro (2011) e Programa de livro popular (Programa de distribuição para as bibliotecas públicas) para literatura compatível com a idade do ensino fundamental I. Assim, criar e fortalecer o hábito de leitura nas crianças, desde a primeira infância, como enfatiza o Manifesto da IFLA/UNESCO sobre Bibliotecas Públicas 1994 (MANIFESTO..., 1995) e, desse modo, influenciar na escolaridade e qualidade da educação. No Brasil, apenas $49 \%$ das bibliotecas públicas têm biblioteca infantil (PRIMEIRO Censo, 2010). Cabe salientar que foi constatada, ainda, uma redução de $9,1 \%$ na quantidade de leitores brasileiros no período de 2007 a 2011, segundo Instituto Pró-Livro (2012); e

\footnotetext{
${ }^{7}$ Vide exemplos de micro políticas públicas em Banerjee e Duflo (2011).

${ }^{8}$ Programa de doação de vale no valor de 50 reais às famílias com renda de até cinco salários para ser gasto em: artes visuais, artes cênicas; audiovisual, literatura e humanidades, música e patrimônio cultural. O projeto, atualmente, encontra-se em discussão no congresso brasileiro.
} 
c) estimular programas de empreendedorismo social (sem verba do governo ou de empresas públicas/economia mistas) de distribuição de livros como o First Book, organização social americana não financiada pelo governo.

Espera-se que os resultados alcançados possam vir a influenciar futuras pesquisas de âmbito estadual ou nacional, buscando tornar os resultados estatisticamente mais robustos ou gerando experimentos para testar as hipóteses ${ }^{9}$.

\section{Referências}

BANERJEE A. V.; DUFLO, E. Poor economics: a radical rethinking of the way to fight global poverty. New York: Public Affairs, 2011.

CARTÃO Livro - Programa para as bibliotecas públicas. Edital de Chamada Pública para Seleção de Livro. Dezembro de 2011. Disponível em: <Sttp://www.bn.br/portal/arquivos/pdf/Minuta\%20do\%20Edital\%204\%2 OPLP.pdf>. Acesso em: 10 dez. 2011.

EVANS, M. D. R. et al. Family scholarly culture and educational success: books and schooling in 27 nations. Research in Social Stratification and Mobility, v. 28, n. 2, p. 171-197, June 2010.

EVANS, M. D. R. et al. To the scholar go the spoils? The influence of parents' scholarly culture on offspring's occupational attainment in 31 societies. August. 2005.

Disponível em: <http://www.ccpr.ucla.edu/publications/conferenceproceedings/CP-05-033.pdf>. Acesso em: 10 nov. 2012.

FIRST Book. Disponível em: <http://www.firstbook.org/>. Acesso em: 5 jan. 2012

GRAAF, N. D. D.; GRAAF, P. M. de; KRAAYKAMP, G. Parental cultural capital and educational attainment in the Netherlands: a refinement of the cultural capital perspective. Sociology of Education, v. 73, n. 2, p. 92111, Apr. 2000.

INSTITUTO PRÓ-LIVRO. Retratos da leitura no Brasil. 3. ed. Disponível em: <http://www.prolivro.org.br/ipl/publier4.0/texto.asp?id=2834>. Acesso em: 5 mar. 2012.

MANIFESTO da Unesco sobre as bibliotecas públicas. 1995. Disponível em: <http://www.bpb.uminho.pt/manifestoUNESCO.htm>. Acesso em:

15 set. 2011.

ORGANISATION FOR ECONOMIC CO-OPERATION AND DEVELOPMENT (OECD). PISA 2009 results: executive summary 2010. Disponível em: <http://www.oecd.org/dataoecd/34/60/46619703.pdf>. Acesso em: 18 abr. 2012

\footnotetext{
9 Possivelmente, servir para orientar algumas das ações deflagradas no plano "O Plano Nacional do Livro e Leitura", recentemente lançado (22 de abril de2012).
} 
ORGANISATION FOR ECONOMIC CO-OPERATION AND DEVELOPMENT (OECD). Programme for International Student Assessment._Disponível em: $<$ (PISA)http://www.pisa.oecd.org/pages/0,3417,en 3225235132235907 11111 ,00.html> . Acesso em: 10 fev. 2012.

PARK ,H. Home literacy environments and children's reading performance: a comparative study of 25 countries. Educational Research and Evaluation, v. 14 , n. 6, p. 489-505, Dec. 2008.

PIEDADE, A. F. Capital cultural como elemento estratificador da sociedade: evidências empíricas em Belo Horizonte. 158 f. Dissertação (Mestrado em Administração) - Faculdade Novos Horizontes, Belo Horizonte, 2009. Disponível em: <http://www.unihorizontes.br/novosite/banco dissertacoes/160820091642351310.pd f>. Acesso em: 15 mar. 2011.

O PLANO Nacional do Livro e Leitura. 22 abril 2012.

Disponível em: <http://www.cultura.gov.br/site/2012/04/23/plano-nacional-do-livroe-leitura-9/>. Acesso em: 30 abr. 2012.

PRIMEIRO Censo Nacional das Bibliotecas Públicas Municipais -2010 MINC/ FGV. Disponível em: < http://www.cultura.gov.br/site/2010/04/30/primeirocenso-nacional-das-bibliotecas-publicas-municipais/>. Acesso em: 10 jan. 2012.

TODOS pela educação 2012. Dados do PISA. Disponível em: <http://www.todospelaeducacao.org.br/comunicacao-emidia/noticias/13951/40-dos-alunos-brasileiros-tem-ate-dez-livros-emcasa-mostra-pisa>. Acesso em: 10 mar. 2012.

WOBMANN, L. Schooling resources, educational institutions

and student performance: the international evidence. Oxford Bulletin Economics and Statistics, v. 65, n. 2, p. 117-170, 2003.

WORLD BANK. Education quality and economic growth 2007. Washington: World Bank, 2007. 28 p. 